\title{
Senkretik Bir Hareket Olarak Mesihi Yahudilik
}

\author{
Messianic Judaism as a Syncretic Movement
}

\author{
Hatice Arslan ${ }^{*}$ (1)
}

Öz

Mesihi Yahudilik, Protestan misyonerlerin Yahudilere yönelik Hıristiyanlaştırma faaliyeti sonucunda din değiştiren Yahudilerin zamanla kendi dini ve milli değerlerinden vazgeçmeden İsa'nın (Yeşua) tanrısal oğul ve beklenen Mesih olduğuna inanmanın mümkün olduğunu savunmaları ve bu görüş çerçevesinde çeşitli birlikler oluşturmaları ile ortaya çıkan yeni bir dini harekettir. Yahudilik ve Hıristiyanlık gibi iki köklü inancı senkretize ederek modern dönemde ortaya çıkan Mesihi Yahudiliğin tarihsel gelişimi ile inanç ve dini uygulamaları bu makalenin konusunu oluşturmaktadır. Bu çerçevede öncelikle Mesihi Yahudiliğin diğer Yahudi Hıristiyan gruplar arasındaki konumu ve hareketin doğuşuna etki eden temel faktörler tespit edilmeye çalışılacaktır. Aynı zamanda hareketin ortaya çıkışının tarihsel süreci kronolojik olarak incelenerek Yahudilerin Hıristiyan olma sürecindeki kırılma noktalarına ışık tutulacaktır. Son olarak Mesihi Yahudilerin inanç ve uygulamaları hakkında bilgi verilecektir.

\section{Anahtar Kelimeler}

Mesihi Yahudilik, Yahudi Hıristiyanlar, Hıristiyanlık, Yahudilik, Yeni Dini Hareketler

\begin{abstract}
Messianic Judaism is a new religion movement that emerged as a result of the Christianization activity of Protestant missionaries. Converted Jews claimed that it was possible to maintain their religious and national values and to believe Jesus (Yeshua) as the divine son. They established various associations within the framework of this view. Syncretizing two essential beliefs such as Judaism and Christianity, emerging in the modern age, the historical development of Messianic Judaism and belief and religious practices are the subject of this article. In this context, firstly, the position of Messianic Judaism among other Jewish Christian groups and the main factors that affect the emergence of the movement will be tried to be determined. At the same time, I will discuss the historical process of the emergence of the movement and the breaking point of the Jews in the Christianization process. Finally, information will be given about the beliefs and practices of the Messianic Jews.
\end{abstract}

\section{Keywords}

Messianic Judaism, Jewish Christians, Christianity, Judaism, New Religious Movement

\footnotetext{
* Sorumlu Yazar: Hatice Arslan (Dr. Öğr. Üyesi), Balıkesir Üniversitesi, İlahiyat Fakültesi,Türkiye. E-posta: hatice.arslan@balikesir.edu.tr ORCID: 0000-0002-0517-8495

Atf: Hatice Arslan, "Senkretik Bir Hareket Olarak Mesihi Yahudilik." darulfunun ilahiyat 31, 2 (2020): 435-456. https://doi.org/10.26650/di.2020.31.2.799877
} 


\section{Extended Summary}

Messianic Judaism is a new religious movement that combines faith in Jesus as Messiah and Son of God with Jewish culture and identity. Messianic Jews insisted on not being regarded as converts to Christianity, but rather as "Completed Jews". Thus they emphasized attachment to their Jewish heritage. They strongly opposed assimilation within Gentile Christian church.

Since the first century of the emergence of Christianity, spreading the message of Christ Jesus to different societies has been accepted as a religious requirement. For, it is stated in the New Testament texts that Jesus wanted his message to be spread among the Israelites before the crucifixion, and then to all nations. Since the Church accepted the Jews as the killers of Christ and the worst enemy of Christianity in the period up to the Reformation, they used force in their mission activities and forced them to convert. With the rediscovery of the Bible after the reform, the attitude towards Jews started to change. Especially within the framework of the influence of Puritanism and the eschatological views of Protestant Evangelists, it is seen that Jewish religious and national values are used in mission activities, emphasizing the historical role of the Jews in the divine plan. The Messianic Judaism, too, emerged as a result of these missions of Christians, and formed various unions in Europe, America, Israel and many other countries throughout the 20th century. Incidents eschatologically associated with the second coming of Christ, such as the establishment of the State of Israel and the Six Day War, encouraged the Jewish Christians to maintain their identity.

This awakening of Jewish national consciousness also led to the emergence of some other Jewish Christian groups. The most important feature that distinguishes the Messianic Jews from other Jewish Christian groups is that they claim that they do not intend to Christianize the Jewish people, but rather try to make them true Jews.

In the early 2000s, there were about 400 Messianic congregations in America, and the number of members of this congregation is higher than the number of Reconstructionist Jews. In Israel, while their number was only a few hundred at the end of the $1960 \mathrm{~s}$, it is estimated that it has exceeded 15,000 since 2010. Messianic Judaism, a movement with a missionary character, accepts members from ethnically Jews and non-Jews.

Although the Messianic Jewish communities put forward quite different opinions from each other in the field of belief, most of them adopt the traditional Christian views on issues such as the divinity of Jesus, the Trinity, the authority of the Bible.

Messianic Jews do not worship in the church but in the synagogue. Although Messianic Jewish synagogues are architecturally different from Jewish synagogues, the layout and objects in them are the same. In the synagogue, the Messianic Jewish rite is led by the religious leader they call the Messianic rabbi, but these rabbis did not grow up in Yeshiva 
as is accepted in traditional Judaism. The most striking aspect of Messianic Jewish worship is prayer, often accompanied by music and dance. For the Messianic Jews, the essence of prayer is to unite with Jesus and pray within him, through him. Jewish worship objects such as tallit and tsitsit are also used during the services.

The vast majority of Messianic Jews celebrate days considered sacred in traditional Judaism. However, the meaning of these holy days in Judaism was interpreted by Messianic Jews in connection with the beliefs of the Christian tradition. Also prayers and hymns especially about Jesus were added to the rituals performed on holy days. Thus, Jesus is placed at the center of every holy day. 


\section{Giriş}

Mesihi Yahudiler, 20. Yüzyılda ortaya çıkan senkretik bir hareket olarak, Yahudilerin uzun zamandır bekledikleri Mesih'in İsa olduğuna inanmakta, bunun yanı sıra Yahudi dini ve ulusal değerlerinin devam ettirilmesi gerektiğini vurgulamaktadırlar. Yahudilik ve Hıristiyanlık gibi iki köklü dini geleneğin doktrinlerini kaynaştıran Mesihi Yahudilik, "geçmişi -kendi ifadeleriyle 'asli geleneği'- tekrar keşfedip bugünkü teolojik ve sosyolojik yapılarına da uygun şekilde inşa etmeye çalışan bir dini hareket olarak karşımıza çıkmaktadır." ${ }^{1} \mathrm{Bu}$ harekette asıl çarpıcı olan Mesihi Yahudilerin, Hıristiyan doktrinlerini Yahudiliğin merkezine yerleştirmesi ve bunun Yahudiliğin yeniden keşfedilen varoluş nedeni olduğuna inanmasıdır. ${ }^{2}$

Bir yandan Kilise, diğer yandan Yahudi din adamlarınca en sert biçimde eleştirilmesine rağmen Mesihi Yahudilik, Amerika' da ve İsrail'de hızla büyümektedir. 2000'lerin başında Amerika' da yaklaşık 400 Mesihi cemaat bulunmaktadır ve bu cemaat mensuplarının sayısı Yeniden Yapılanmacı Yahudilerin sayısından daha fazladır. İ́srail'de ise 1960 'lı yılların sonunda yalnızca birkaç yüz olan Mesihi Yahudilerin nüfusunun, 2010 y1lından itibaren 15.000 'i aştığ 1 tahmin edilmektedir. ${ }^{4}$ Misyoner karakterli bir hareket olarak Mesihi Yahudilik, etnik olarak Yahudi olanların yanı sıra Yahudi olmayanlardan da üye kabul etmektedir.

Bu makalede "Mesihi Yahudiliğin modern dönemde ortaya çıkan Yahudi Hıristiyan hareketlerden farkları nelerdir?", "Hareketin tarihsel kökeni nedir?", "Bu hareketi doğuran temel sebepler nelerdir?", "Kendisini hangi dini grup ile ilişkilendirmektedir?", "Senkretik bir hareket olarak Mesihi Yahudiliğin doktrin ve uygulamaları ile Hiristiyanlık ve Yahudiliğin doktrin ve uygulamaları arasında benzerlikler ya da farkl11ıklar nelerdir?" sorularına cevap aranarak bu grubun tanınmasına katkı sağlanması hedeflenmiştir.

1 Bülent Şenay, “19. ve 20. Y.Y.’da Mûsevî-Hıristiyanlar-Hibridite, Dînî Kimlik ve Gelenek-”, 2000. Yllında Hıristiyanlık (Dünü, Bugünü ve Geleceği), Dinler Tarihi Araştırmaları-III (Sempozyum, 09-10 Haziran 2001, Ankara), (Ankara: Dinler Tarihi Derneği Yayınları/3, 2002), 61.

2 Rachael L.E. Kohn, "Ethnic Judaism and the Messianic Movement", The Jewish Journal of Sociology, 29/2 (1987), 86.

3 Yaakov Ariel, "Judaism and Christianity Unite! The Unique Culture of Messianic Judaism", Introduction to New and Alternative Religions in America, ed. Eugene V. Gallagher, W. Michael Ashcraft, (London: Greenwood Press, 2006) 2/191.

4 Ariel, “A Different Kind of Dialogue? Messianic Judaism and Jewish Christian Relations". Cross Currents 62/3 (2012), 323 


\section{Mesihi Yahudilik: Kavramsal Çerçeve}

Protestan Hıristiyanların Yahudilere yönelik misyonerlik faaliyetleri 16. yüzyıla kadar geri gitmektedir. ${ }^{5} 19$. Yüzyılda Dünya genelinde Hıristiyanlığı kabul eden Yahudilerin sayısı 224.000 civarındayken, 20. yüzyılın ilk yıllarında çoğunluğu Avrupa'da olmak üzere Avrupa ve Amerika'da 230.000 Yahudinin, Hıristiyanlığa geçtiği tahmin edilmektedir. ${ }^{6}$ Hıristiyanlığ din olarak benimseyen Yahudiler zamanla Kiliseye bağl1/ bağımsız günümüzde özellikle Amerika'da ve İsrail'de faaliyet gösteren çeşitli gruplar oluşturmuşlardır. Makalemizin konusunu oluşturan Mesihi Yahudilik hareketini ise diğer Yahudi Hıristiyan gruplardan ayıran bazı temel farklar bulunmaktadır.

Mesihi Yahudiler, 19. yüzyılda Anglikan Kilisesi'nin Yahudilere yönelik misyonerlik faaliyetlerinin yoğun olduğu bir dönemde kendilerini "İbrani Hıristiyanlar" olarak adlandıran küçük bir gruptan doğmuş ve 1960'lara doğru daha belirgin bir dini harekete dönüşmüştür. I İbrani Hıristiyanlar Protestan kilisesi içindeki Yahudi milli kimliğini ön plana çıkaran inananları ifade etmektedir. ${ }^{8}$ İbrani Hıristiyanlar da tıpkı Mesihi Yahudiler gibi kendilerini “Nasıralı İsa'nın (Yeşua) Tanrı Oğlu, Kurtarıcı ve Mesih olduğuna iman etmeyi gönüllü olarak kabul eden Yahudiler ${ }^{9}$ șeklinde tanımlamakta ve Yahudilerin uzun zamandır bekledikleri Mesihin İsa olduğunu, böylece İsa'nın Mesihliği düşüncesiyle Yahudiliğin bağdaştığını ileri sürmektedir. ${ }^{10}$ Mesihi Yahudilerin, İbrani Hıristiyanlardan ayrı bir grup olarak kendilerini tanımlamalarının temel nedeni yalnızca Yahudilerle aralarında ulusal ve kültürel bir bağa vurgu yapmaları değil aynı zamanda Yahudi dini geleneğini de sürdürme arzularıdır. İbrani Hıristiyanlar arasında geleneksel Yahudi uygulamalarına devam edenlerin kendileri için "Mesihi Yahudi" terimini kullanmaları 20. yüzyılın ilk yarısında Filistin topraklarındaki Yahudi Hıristiyanlara kadar geri gitmektedir. ${ }^{11}$ Filistin bölgesinde İsa'ya inanan Yahudiler, özellikle

5 Hıristiyanların Yahudilere yönelik misyonerlik faaliyetleri ve kurdukları misyon organizasyonları için bkz. W.T. Gidney, Missions to Jews, (London: London Society for Promoting Christianity amongst the Jews, 10. Bask1, 1912.

6 Mitchell L. Glaser, "A Survey of Missions to the Jews in Continental Europe 1900-1950", (Doktora Tezi, Fuller Theological Seminary, Faculty of the School of World Mission, 1998), 15 aktaran: Ramazan Adıbelli, “İsa’nın 'Meşiah’a Dönüşümü: Mesihi Yahudilikte Mesihlik Fenomeni”, Insan ve Toplum Bilimleri Araştırmaları Dergisi, 5/2 (2016), 256.

7 Şenay, “19. ve 20. Y.Y.'da Mûsevî-Hıristiyanlar, 58.

8 Daniel Juster and Peter Hocken, The Messianic Jewish Movement: An Introduction, 2004, 6.

9 Gershon Nerel, “ 'Messianic Jews' in Eretz-Israel (1917-1967) Trends and Changes in Shaping Self Identity”, Mishkan 27 (1997), 11.

10 Ramazan Adıbelli, “İsa’nın 'Meşiah’a Dönüşümü”, 245.

11 Bkz. Yaakov Ariel, An Unusual Relationship: Evangelical Christians and Jews, (New York and London: New York University Press, 2013, 217-218. 
İbranice konuşurken ya da İbranice yayınlarda Hıristiyan (notzrim) kelimesini kullanmamaya özen göstermişlerdir. ${ }^{12}$ Çünkü bu ülkedeki Yahudiler için Hıristiyan kelimesi bütünüyle yabancı ve düşman bir dini ifade etmektedir. Böylece misyonerler daha tarafsız, olumsuz duygular uyandırmayan bir terim aramış,

Hıristiyan teriminin taşıdığı şüphe ve karşıtlığın üstesinden gelmek için Mesihi (meşihyim) terimini seçmişlerdir. ${ }^{13}$ Mesihi Yahudi teriminin Amerika'da kullanılması ise 1970'li yıllarda gerçekleşir. ${ }^{14}$ Resmi olarak bu hareket için kullanılması ise çok daha sonra, 1997'de Meksika'da gerçekleşen uluslararası konferansta kabul edilmiştir. ${ }^{15}$ İbrani Hıristiyanlar geleneksel olarak yerel kilise cemaatlerine katılırken Mesihi Yahudi gruplar kiliseden bağımsız cemaatler kurmuşlardır. Dahası Mesihi Yahudiler kilise uygulamalarının doğasını ve uygulamasını sorgulamış ve çoğunlukla bu uygulamaların Yahudilik içindeki uygulamalardan daha az Kutsal Kitap'a dayalı olduğunu ifade etmişlerdir. ${ }^{16}$

Mesihi Yahudiler ile benzerlik gösteren bir diğer grup "İsa'nın Yahudileri”dir (Jews for Jesus). İsa'nın Yahudileri 1970'li yılların başında Moishe Rosen (19322010) tarafindan misyoner bir hareket olarak kurulmuştur. Bu dini hareket, Mesihi Yahudiler gibi İbraniceyi ve Yahudi sembollerini etkin bir biçimde kullanmaktadır. Ancak Mesihi Yahudilerin aksine İsa'nın Yahudileri, tıpkı İbrani Hıristiyanlar gibi mensuplarının yerel Protestan kiliselere katılmasını istemektedir. ${ }^{17}$ Ayrıca bu grubun temel hedefi Yahudilerin Hıristiyanlığı kabul etmesini sağlamaktır. Pek çok Hıristiyan, İsa'nın Yahudileri terimini Mesihi Yahudiler ile eşanlamlı olarak kullanır ve Mesihi Yahudiliğin temelde Yahudileri Hıristiyanlara dönüştürmek için bir misyoner strateji olduğunu varsayar. ${ }^{18}$ Mesihi Yahudiler ise bu fikre karş1 çıkarak kendi amaçlarının Yahudileri Hıristiyanlaştırmak değil aksine onları "gerçek Yahudi" haline getirmek olduğunu iddia etmektedir. ${ }^{19}$

Mesihi Yahudiler kendilerini hem tam bir Hıristiyan hem de tam bir Yahudi olarak görmektedir. Bu yönüyle Mesihi Yahudiler "İbrani Katolikler” (Hebrew

12 Nerel, “"Messianic Jews' in Eretz-Israel”, 12-13.

13 Ariel, "Judaism and Christianity Unite!", 194.

14 Yaakov Ariel, Evangelizing the Chosen People, (USA: The University of North Carolina Press, 2000), 223.

15 Nerel, “ “Messianic Jews' in Eretz-Israel”, 13.

16 Bülend Senay, "The Making of a Tradition: Jewish Christianity”, Mishkan 27, (1997), 33.

17 Yaakov Ariel, "Messianic Judaism”, The Jewish Annotated New Testament, Ed. Amy-Jill Levine and Marc Zvi Brettler, (New York: Oxford University Press, 2011), 757.

18 Mark S. Kinzer, "Twenty-First Century Messianic Judaism: Evangelical and Post EvangelicalTrajectories", Hebrew Studies 57, 2016, 360.

19 Senay, "The Making of a Tradition: Jewish Christianity”, 33. 
Catholics) ile teolojik açıdan benzerlik gösterir. Ancak İbrani Katolikler, Katolik Kilisesi içinde yarı bağımsız bir kilise olarak varlıklarını sürdürürken; ${ }^{20}$ Mesihi Yahudiler, kiliselerden bağımsız organizasyonlar kurmaya çalışır ve oluşturdukları organizasyonlar için "Kilise" kelimesini kullanmak yerine, "kardeşlik", "birlik", "ittifak", "dernek" ya da "Hıristiyan sinagogu" gibi terimler kullanırlar. ${ }^{21}$ Bununla birlikte iki grupta kendi üyelerinin Gentile kilise içinde asimile olmasına itiraz etmektedir. Yine iki grup da etnik kimliklerini ön plana çıarmaktadır. Gerek Mesihi Yahudiler gerekse İbrani Katolikler İsa'nın takipçisi diğer bütün milletler arasında tanıının "seçilmiş halkı" olarak eşsiz bir konumda oldukları iddiasındadırlar. ${ }^{22}$

\section{Mesihi Yahudiliğin Tarihsel Arka Planı ve Ortaya Çıkışı}

Modern dönemde ortaya çıkmış yeni bir dini hareket olan Mesihi Yahudilik kendi kökenini İsa'nın ilk inananlar topluluğuna kadar geri götürmektedir. Nitekim Hz. İsa'ya ilk inananların etnik olarak Yahudi olduğu ve Yahudi dini geleneğini sürdürdügü bilinmektedir. Hz. İsa sonrası Gentileler arasında Hıristiyanlığın yayılmasıyla birlikte havariler arasında bazı fikir ayrılıkları oluşmuştur. Bunlardan özellikle Pavlus önderliğindeki Helenistik Antakya cemaati ile erken dönem kilise yazarlarının Yahudi Hıristiyan olarak adlandırdığı Yakub önderliğindeki Kudüs cemaatinin Gentile Hıristiyanların Yahudi dini geleneğini sürdürme konusunda birbirlerine muhalif olduğu görülmektedir. Gentilelerin Musa şeriatinden sorumlu olmadı̆̆ını savunan Pavlusçu anlayışın tarihsel süreçte Roma topraklarına yayılmasıyla birlikte Yahudi geleneğini sürdüren Yahudi Hıristiyan gruplar heretik kabul edilmiş ve zamanla yok olmuştur. ${ }^{23} 4$. yüzyıldan itibaren Roma İmparatorluğu'nda büyük bir güç haline gelen Gentile Kilisesi Hıristiyanlaştırılan/ Hıristiyanlığı seçen Yahudilerin asimile olmasını gerekli görmüş ve onları Yahudi eğilimlerinden uzaklaştırmaya çalışmıştır. ${ }^{24}$ 5. yüzyılda Batı Roma’nın yıkılmasıyla birlikte siyasi olarak da güçlenen kilise ve papalık Hıristiyanlığın yayılması için

20 Nerel, "Messianic Jews' in Eretz-Israel”, 13.

21 Gershon Nerel, “Attempts to Establish a "Messianic Jewish Church” in Eretz-Israel”, Mishkan 28 (1998), 29.

22 Gershon Nerel, “ 'Messianic Jews' in Eretz-Israel, 13.

23 Şinasi Gündüz, Hıristiyanlık, (İstanbul: İsam Yayınları, 2020), 35;. Ömer Faruk Harman, "Yahudi Hıristiyanlığı", TDV İslam Ansiklopedisi, 43, 186. Fruchtenbaum'un ifadesine göre Hıristiyanlığın daha ilk yüzyılından ilk Yahudi Hıristiyan hareketin ortaya çıktığı 1800'lü yıllara kadar takip edilebilir bir çizgisi vardır. Yüzlerce yıl Yahudi geleneğinden kopmadan Hıristiyan olmuş kişilerin izini sürmek mümkündür. Arnold G. Fruchtenbaum, Hebrew Christianity: Its Theology, History and Philosophy, (Michigan: Baker Book Hause, 1974), 43-48

24 Fruchtenbaum, Hebrew Christianity: Its Theology, History and Philosophy, (Michigan: Baker Book Hause, 1974), 46-47. 
misyonerlik faaliyet alanlarını genişletmiştir. Özellikle Ortaçağ boyunca Hıristiyan egemenliğindeki Avrupa'da Yahudiler sürgün ya da işkenceye maruz kalmış ve çoğunlukla din değiştirmeye zorlanmıştır. ${ }^{25}$ Bunun yanı sıra bir hayatta kalma stratejisi olarak da Yahudiler din değiştirmeyi seçmiş, böylece kripto Yahudiler olarak adlandırılan dini gruplar ortaya çıkmıştır. ${ }^{26}$

15. ve 16. yüzyılda Hıristiyanların Yahudilere karşı tutumunda farklılıklar oluşmuştur. Bunun öncelikli nedenlerinden biri Rönesansın etkisiyle İbranice’ye olan ilginin artması ve Yahudi dini kaynaklarının Hıristiyanlık için kullanılmasıdır. $\mathrm{Bu}$ durum yüzyıllardır süren düşmanlığa rağmen Yahudi alimlerle Hıristiyanların işbirliğini gerekli kılmıştır. ${ }^{27}$ Ayrıca Reformasyon ile birlikte Yahudilerin din değiştirmesi için güç kullanmak yerine onların ikna yoluyla kazanılması hedeflenmiştir. Reform hareketinin öncülerinden Martin Luther, Katolik Kilisesi'ne karşı yeni bir din anlayışı getirmiş ve bu anlayış için taraftar kazanma arzusunda olmuştur. ${ }^{28}$ Onun 1523 'de yazdı̆̆ 1 "Dass Jesus Christus Ein Geborener Jude Sei" (İsa Mesih Doğuştan Bir Yahudiydi) adlı eserinde Yahudilere nazik davranıldığı ve onlara Yeni Ahit’ten bilgi verildiği takdirde gerçek Hıristiyan olacaklarını ve böylece atalarının imanına geri döneceklerini söyler. ${ }^{29}$ Luther eserinde din değiştiren Yahudileri eski dindaşlarını kazanmalarına yardımcı olması için kullanmayı önermiştir. Bu, yöntem daha sonra, çok sayıda Protestan grup tarafindan da kullanılmıştır. ${ }^{30}$

25 Gündüz, Hıristiyanlık, 44.

26 Patricia A. Power, "Blurring the Boundaries: American Messianic Jews and Gentiles", Nova Religio, 15/1, August 2011, 74. 14. ve 15. yüzyıllarda İspanya ve Portekiz'de Yahudileri Katolikleştirme politikasının sonucu olarak ortaya çıkmış bir kripto Yahudi dini grup için bkz. Mahmut Salihoğlu, "Marranolar ve Dini İnançları”, Ekev Akademi Dergisi 15/49, (Güz 2011), 105-115.

27 Jerome Friedman, "The Myth of Jewish Antiquity: New Christians and Christian-Hebraica in Early Modern Europe", Jewish Christians and Christian Jews From the Renaissance to the Enlightment, ed. Richard H. Popkin and Gordon M. Weiner, (Kluwer Academic Publishers, 1994), 35 .

28 Hakan Olgun, Sekülerliğin Teolojik Kurgusu: Protestanlı, (İstanbul: İz Yayıncılık, 2006), 318.

29 W. T. Gidney, The History of the London Society for Promoting Christianity Amongst the Jews from 1809 to 1908, (London: London Society for Promoting Christianity Amongst the Jews, 1908), 8

30 B. Zvi Sobel, "Jews and Christian Evangelization: The Anglo-American Approach", American Jewish Historical Quarterly, 58/2 (December, 1968), 246. Yahudilerden beklediği ilgiyi göremeyen Luther 1542'de yayınladığı bir başka çalışmada (The Jews and their Lies) bu fikirlerinden vaz geçmiş ve ayırım yapmaksızın bütün Yahudilere saldırmıştır. Olgun, Protestanlık, 319. Luther'in bu düşmanca ifadelerine rağmen Lutheran Protestanlar Yahudilere yönelik misyon faaliyetlerine devam etmiştir. 
17. yüzyıla gelindiğinde Puritanların Yahudilere yönelik ilgilerini görüyoruz. Onların bu ilgilerinin temelinde Kutsal Kitap'ın literal olarak yorumlanmasıly birlikte Yahudilerin Mesihi çağdaki rolünün ön plana çıkması yatmaktadır. ${ }^{31}$ Puritanların eskatolojik yorumuna göre İsa'nın dönüşünün habercisi olarak Yahudilerin Hıristiyanlığa geçmesi ve Kutsal Topraklar'a yeniden dönmeleri gerekir. ${ }^{32}$ Yine bu dönemde Mesih' in yakın bir zamanda geleceği/yeniden geleceği beklentisi hem Yahudiler hem de Hıristiyanlar arasında artmıştır. İşte bu ortak umut iki grubu birbirine yaklaştıran bir diğer etkendir. ${ }^{33}$

Puritanların İsa'nın gelişis ile ilgili bu umudu 18. yüzyıl başlarında Lutheran Pietizmine ve Moravya hareketine yayılmıştır. ${ }^{34}$ Pietist bir papaz olan Johann Müller'in (1649-1727) yazdığı Or le-et 'erev (Akşam Vaktinin Işı̆̆ı) risalesi din değiştiren Yahudilerin sünnet geleneği ve Torah'a uymayı sürdürmeleri hakkını korumay1 savunan Institutum Judaicum'un (1728) kurulmasına öncülük etmiş, bu kurum 1792 yılına kadar pek çok misyoner yetiştirmiş ve farklı ülkelere göndermiştir. ${ }^{35}$ Yine Almanya Herrnhut’ta, başından beri kendini Yahudilere yönelik misyonerliğe adayan Moravya kilisesi piskoposu Nikolaus Ludwig von Zinzerdof 1700'lü y1llarda Yahudi kimliği ve yaşam biçiminden ayrılmadan İsa'ya inanan Yahudiler için Judenkehille (Yahudi cemaati) adında bir topluluk kurmuştur. ${ }^{36} \mathrm{Bu}$ dönemden sonra artık Yahudilerin "dönüştürülmesi” için pek çok merkez kurulur. Bu

31 Ariel, An Unusual Relationship: Evangelical Christians and Jews, 35-36.

32 Ariel, An Unusual Relationship: Evangelical Christians and Jews, 23.

33 Richard H. Popkin, "Christian Jews and Jewish Christians in the 17th Century", Jewish Christians and Christian Jews From the Renaissance to the Enlightment, ed. Richard H. Popkin and Gordon M. Weiner, (Kluwer Academic Publishers, 1994), 57; Şenay, “19. ve 20. Y.Y.'da MûsevîHiristiyanlar"62, 63.Bir Marrano olark doğan Manasseh Ben Israel (1604-1657) Kabalistik hesaplamaları doğrultusunda Mesih'in geliş tarihi olarak 1648 yılını gösterir. Ayrıca Tesniye 28:64'de yer alan "Ve rab sizi, yerin bir ucundan öbür ucuna kadar bütün milletler arasında dağıtacak" şeklindeki ifadeye dayanarak, Yahudiler dünyanın en uç noktasına kadar dağılmadıkça Mesih'in gelişinin gerçekleşmeyeceğini iddia etmiştir. Manasseh'in bu görüşleri İngilteredeki Puritan Hıristiyanlarca' da kabul görür ve İngiltere'ye Yahudilerin gelmesi teşvik edilir. Cengiz Batuk, Tarihin Sonunu Beklemek: Ortadoğu Dinlerinde Eskatoloji Mitoslarl, (İstanbul: İz Yayınc1lik, 2003) 107-108.

34 Juster and Hocken, The Messianic Jewish Movement, 12.

35 Lutz Greisiger, "Israel in the Church and the Church in Israel: The Formation of Jewish Christian Communities as a Proselytising Strategy Within and Outside The German Pietist Mission to the Jews of the Eighteenth Century", Pietism and Communityin Europe and North America, 1650-1850, ed. Jonathan Strom, (Leiden, Boston: Brill, 2010), 130.

36 Greisiger, "Israel in the Church and the Church in Israel", 138; David Rudolph, "Messianic Judaism in Antiquity and in the Modern Era", Introduction to Messianic Judaism: Its Ecclesial Context and Biblical Foundations, ed. David Rudolph \& Joel Willits, (Grand Rapids: Zondervan, 2013), 25-26. 
merkezlerde Yahudilerin barınma ve yaşam koşullarını iyileştirmeye yönelik hizmet verilmiş; böylece Avrupa' da güç şartlar altında bulunan Yahudilerin cezbedilerek din değiştirmesi hedeflenmiştir. ${ }^{37}$

Mesihi Yahudiliğin doğuşuna zemin hazırlayan bir diğer etken Evanjelizmin yükselişidir. 19. yüzyılın ilk yıllarından itibaren Evanjelikalizm, Anglikan Kilisesi'nin kurumlarına sızmış ve İngiltere'de büyük bir güç haline gelerek Yahudilerin Hıristiyanlaştırılmasına hız vermiştir. ${ }^{38}$ Yahudileri seçilmiş halk olarak kabul eden Evanjelikler'e ${ }^{39}$ göre, Tanrı'nın İbrahim'le yaptığı antlaşma geçici olarak askıya alınsa bile hala geçerlidir. Yahudiler, Tanrı ile İsrail arasında yapılan ahdin mirasçıları olarak yeniden kurulacak bir Davut krallığı için Kutsal Kitap kehanetlerinin objesidir. ${ }^{40}$ Aynı zamanda, Yahudilerin diğer tüm insanlar gibi, kurtulabilmesi için İsa'yı kurtarıcıları olarak kabul etmeleri zorunludur. Bu nedenle Evanjelikler, 19. yüzyılda Yahudi kimliğini, geleneklerini ve sembollerini koruyarak Yahudi Hıristiyan topluluklar kurmaya çalışmışlardır. ${ }^{41} \mathrm{Bu}$ çerçevede İngiltere' de pek çok misyon örgütü kurulmuştur. ${ }^{42} \mathrm{Bu}$ örgütler arasında günümüzde "Church's Ministry Among Jewish People" (CMJ=Yahudi Halk Arasında Kilise Hizmeti) adını alan "London Society for Promoting Christianity Amongst Jews" (LSBCJ= Yahudiler Arasında Hiristiyanlığ 1 Yayma Londra Cemiyeti), en eski ve en yaygın misyon kuruluşudur. Anglikan Kilisesi'ne bağlı olan bu cemiyet Yahudi bir ailede doğan, fakat daha sonra Hıristiyan olan Joseph Frey (1771-1850) tarafindan 1809 yılında kurulmuştur. Burada hem Gentile Hıristiyanlar hem de Yahudi Hıristiyanlar misyoner olarak çalışmaktadır. Bu merkezde özellikle fakir Yahudi ailelerin çocuklarına eğitim veren okullar bulunmaktadır. 1817'de Yeni Ahit, 1826'da ise Hiristiyan kutsal kitabının tamamı İbranice olarak basılmış ve bunların Yahudi eğitim kurumlarında okutulması LSBCJ'nin çabaları ile

37 17. ve 18. yüzyıllarda Yahudilere yönelik misyonerlerin kurdukları merkezler ve bu merkezlerin hizmetleri ile ilgili bkz. Anke Költsch, "Foundations, İnstitutes, Charities, and Proselytes in the Early Modern Holy Roman Empire”, Jewish History, 24 (2010), 87- 104.

38 Mustafa Kaan Sağ, "Londra Yahudiler Cemiyeti İstanbul Misyonu ve Hasköy İngiliz Okulu”, Belleten 79/285, Ağustos 2015, 630.

39 Mesih İsa'nın ikinci gelişinin zamanıyla ilgili Evanjelikler arasındaki farklı görüşlerden dolayı çeşitli gruplara ayrılmışlardır. Premilenyalist Evanjelikler, İsa'nın bin yıllık dönemden önce geri dönebileceğini savunurken Postmilenyalist Evanjelikler bin yıllık dönem bitmeden İsa’nın gelmeyeceğini düşünmektedir. Aralarındaki bir diğer fark da Premilenyalistler bin yıllık dönemde bu dünya kıtlık, afetler nedeniyle 1stırap çekebileceğine inanmış; Post milenyalistler ise bin y1llık dönemin bir altın çağ olduğunu savunmuştur. Ayrıntılı bilgi için bkz. Güngör, Evanjelikler, 194-196.

40 Ariel, "Judaism and Christianity Unite!”, 192.

41 Yaakov Ariel, "A Different Kind of Dialogue? Messianic Judaism and Jewish Christian Relations", CrossCurrents. 62/3, (2012), 318- 319.

42 İngiltere'de kurulan misyon örgütleri için bkz. Gidney, The History of the London Society for Promoting Christianity Amongst the Jews from 1809 to 1908, 11-12; Missions to Jews, 78-89. 
sağlanmıştır. ${ }^{43}$ Böylece Yahudi halkın Hıristiyan kutsal metinlerini tanıması, dolayısıyla Hıristiyan olmasının kolaylaşması hedeflenmiştir. LSBCJ'nin bir diğer önemli özelliği merkezin içinde Episkopal Yahudileri Şapeli’nin bulunmasıdır. Bu şapel hem Yahudileri kazanmaya çalışan hem de din değiştirenleri ağırlamak için tasarlanmış bir Anglikan ibadet merkezi olması bakımından benzersizdir. Şapel, Yahudilere ve Gentile Hıristiyanlara hizmet vermekle birlikte bir süre sonra Yahudilerin yoğunlukta olduğu bir kuruluşa dönüşür. Zamanla çeşitli Yahudi sembolleri de kilisenin iç ve dış kısmında görünür hale gelir. ${ }^{44}$ Şapel'in bu şekilde "Yahudileştirilmesi”nin sebebi muhtemelen son yüzyılda Puritanizmin yükselişine bağlıdır. Puritanizmin etkisiyle Yahudi kimliğinin yeniden öne çıkması, merkezdeki Yahudi Hıristiyanların bir arada bulunma bilincini canlandırmış olmalıdır. Nitekim 9 Eylül 1813'de LSBCJ'ye mensup kırk bir Yahudi Hıristiyan bir araya gelerek İbrani Hıristiyan (Hebrew Christian) hareketinin de temelini oluşturan "B'nei Abraham" derneğini kurmuştur. Bu grup, her Pazar sabahı ve her Cuma akşamı Yahudi Şapeli'nde dua etmek için bir araya gelmiş, ayrıca hasta olan üyelerini günlük olarak ziyaret ederek onlara Kutsal Kitap'tan pasajlar okumuştur. ${ }^{45}$

Daha çok bir sosyal yardımlaşma derneği gibi hizmet eden ${ }^{46}$ bu ilk Yahudi Hıristiyan topluluğun ardından 1860'lı yıllarda S.C. Schwartz, farklı Protestan kiliselere mensup olan tüm Yahudi Hıristiyanları aynı çatı altında birleştirmek istemiştir. Bu birlikteliği sağlamaktaki temel amaç Yahudi Hıristiyanların ihtiyaçlarını görüşmek, Yahudiler arasında Hıristiyan misyonerliğini güçlendirmek ve teolojik konulardaki fikirleri tartışmaktır. ${ }^{47}$ Böylece seksen kişilik bir Yahudi Hıristiyan grup 1866 'da Schwartz'1n önderliğinde bir araya gelerek "Hebrew Christian Alliance of Great Britain” (HCA=Büyük Britanya'nın İbrani Hıristiyan Birliği)'1 kurar. ${ }^{48}$

43 Gidney, Missions to Jews, 76.

44 Rodney Curtis, "Evangelical Anglican missionaries and the London Jews Society: Palestine Place at Bethnal Green and related developments, 1813-1895", Jewish Historical Studies 50/1 (2018), 76-77.

45 Gidney, The History of the London Society for Promoting Christianity Amongst the Jews from 1809 to 1908, 43. Bu dernek 1835 y1lından sonra "Episcopal Jews' Chapel Abrahamic Society" olarak tanınmıştır. Cohn-Sherbok, Messianic Judaism, (London and New York: Continuum, 2000), 16.

46 Şenay, "19. ve 20. Y.Y.'da Mûsevî-Hıristiyanlar, 63.

47 Juster and Hocken, The Messianic Jewish Movement, 13.

48 Dan Cohn-Sherbok, "Modern Hebrew Christianity and Messianic Judaism", The Image of the Judaeo-Christians in Ancient Jewish and Christian Literature. Ed. Peter J. Tomson \& Doris Lambers-Petry, (Tübingen: Mohr Siebeck, 2003), 287-288. İngiltere'de kurulan bu birliğin az ya da çok çeşitli kiliselerle olumlu ilişkileri vardır. Rabinowitz tarafından 1882'de Kishinev'de kurulan Israelites of the New Covenant adlı grup herhangi bir kilise ile bağı olmayan ilk Yahudi Hıristiyan kuruluşudur. Cohn-Sherbok, Messianic Judaism, 18. 
İngiltere' de kurulan bu birlikten sonra Amerika'da bulunan Yahudi Hıristiyanların bir araya gelmesiyle 1915'de "Hebrew Christian Alliance of America" (HCAA= Amerikan İbrani Hıristiyanlar Birliği) kurulur. Din değiştiren Yahudileri bir araya getiren bu kuruluş Amerika'da hızla büyümüştür. 1920'de bir kilise ya da bir mezhep olmadıklarını, bir misyoner kuruluşu olarak amaçlarının Yahudi halkı Hıristiyanlaştırmak olduğunu ilan etmişlerdir. ${ }^{49}$ Yahudi Hıristiyanların kurduğu bu birlikler temelde ayrı bir kilise kurma hedefi gütmemiştir. Onlar, din değiştiren Yahudilerin Protestan kiliselere devamını desteklemiştir.

Protestan kilisesinden bağımsız, ilk Mesihi sinagogun Joseph Rabinowitz tarafından 1882'de Kishinev'de kurulan “Bney Israel” olduğu ifade edilmektedir. Rabinowitz, Israelites of the New Covenant adlı bir cemaat kurmuş ve cemaat üyelerini Yahudi dini uygulamalarından sorumlu tutmuştur. ${ }^{50}$ Rabinowitz' in kurduğu bu topluluk herhangi bir Hıristiyan kilise ile bağı olmayan ilk Yahudi Hıristiyan cemaat olması bakımından önemlidir. Rabinowitz, kendi döneminde Yahudi dini uygulamalarının yerine getirilmesi gerektiğini düşünen az sayıda Yahudi Hıristiyandan biridir. Ancak onun görüşleri Avrupa ve Amerika'daki Yahudi Hıristiyan cemaatleri de etkilemiş görünüyor. 1901 yılında Amerikalı Yahudi Hıristiyanların toplandığı bir kongrede, cemaat içinde Rabinowitz örneğindeki gibi kiliseden bağımsız Yahudi geleneğini sürdürmek isteyenlere karşı bir tepki oluştuğu bilinmektedir. ${ }^{51} \mathrm{Bu}$ yıllarda cemaat içi ortaya çıkan ayrılıklar bastırılabilmiş ve 1915 'te resmi olarak kurulan HCAA kiliseye olan bağlıllı̆ını ilan etmiştir. Ancak 1960'lı yıllarda uygun ortamın oluşmasıyla birlikte kiliselerden bağımsız, Yahudi eğilimlerin öne çıktığı görüşler HCAA'da köklü bir değişiklik meydana getirecektir.

HCAA'da çarpıcı bir biçimde değişikliğe neden olan etkenlerden biri Amerika'da faaliyet gösteren American Board of Missions (Amerikan Misyonlar Kuruluşu) gibi bazı misyon kuruluşlarının çabalarıyla 1967-1974 yılları arasında çok sayıda genç Yahudinin Hıristiyan olmasıdır. HCAA'ya katılan bu genç Yahudiler kendi dini ve milli kimliklerinden vaz geçmek istememiştir. Zira 1948'de İsrail Devleti'nin kurulması; 1967'de Altı Gün Savaşı'nda İsrail'in Arap ülkelere karşı zaferi ile Kudüs'ün yeniden İsrail hakimiyetine girmesi Kutsal Kitap kehanetlerinin gerçekleşmesi olarak yorumlanmış.52 böylece Yahudi gençler, kendi dini ve milli kimliklerinden vazgeçmeden Hıristiyanlığı kabul etmiş ve HCAA'ya katılmıştır. 1975'de yapılan HCAA konferansında misyoner kuruluşunun adı, organizasyondaki genç Mesihi

49 Cohn-Sherbok, "Modern Hebrew Christianity and Messianic Judaism”, 289.

50 Cohn-Sherbok, Messianic Judaism, 18.

51 Bkz. Cohn-Sherbok, "Modern Hebrew Christianity and Messianic Judaism”, 288.

52 Ariel, "Messianic Judaism”, 757; Power, "Blurring the Boundaries: American Messianic Jews and Gentiles", 78. 
Yahudilerin etkisiyle Messianic Jewish Alliance of America (MJAA=Amerikan Mesihi Yahudi Birliği) olarak değiştirilmiştir. ${ }^{53} \mathrm{Bu}$ isim değişikliği aynı zamanda temelleri 1800'lü y1llarda atılan İbrani Hıristiyan hareketinin Yahudi geleneğine yaklaşacağının da göstergesidir. Nitekim "İbrani Hıristiyan" isminde vurgu daha çok Hıristiyanlığa iken "Mesihi Yahudi" ismi Yahudiliği öncelemektedir. HCAA içindeki genç Yahudi Hıristiyanlar, hareketin mensuplarının Yahudi uygulamalarını ve yaşam tarzını sürdürmeleri gerektiğini savunmuşlardır. Ayrıca dua esnasında Yahudilerin geleneksel kıyafetlerini kullanma, İbranice şarkı söyleme ve bu unsurları evanjelik ibadette olduğu gibi müzik ve alkış ile birleştirerek ayine yeni unsurlar eklemişlerdir. ${ }^{54}$ $\mathrm{Bu}$ şartlarda grubun çok sayıda yaşlı üyesi birlikten ayrılmayı tercih etmiştir. ${ }^{55}$

1979 yılında Mesihi cemaatleri tek bir çatı altında toplama amacıyla Union of Messianic Jewish Congregations (UMJC=Mesihi Yahudi Cemaatler Birliği) kurulmuştur. Bu birliğe mevcut yirmi bir cemaatten on dokuzu katılmıştır. Bunu 1986'da on beş cemaatle International Assocation of Messianic Congregations and Synagogues (IAMCS=Uluslararası Mesihi Cemaatler ve Sinagoglar Derneği) izlemiştir. 2012'de bu iki çatı örgütün iki yüzden fazla Mesihi cemaati temsil ettiği kaydedilmektedir. Ayrıca dünya çapında bağımsız veya daha küçük Mesihi Yahudi birliklere bağlı üç yüzün üzerinde cemaat vardır. ${ }^{56}$

Mesihi Yahudi hareketi hem Hiristiyanlar hem de Yahudiler tarafindan şiddetle eleştirilmektedir. Hıristiyan misyonerler, Mesihi Yahudiliği Hıristiyan mezheplerinin himayesi dışında bir cemaat organizasyonu oluşturduğu için varlığını onaylamamaktadır. ${ }^{57}$ Ayrıca Hıristiyanlar, Yahudi dini geleneğini sürdürmenin İsa'nın mesajına zarar vereceğini savunmaktadırlar. Diğer yandan Hümanist Yahudiler dışındaki Yahudi gruplar Mesihi Yahudileri Hıristiyan misyonerler olarak kabul etmektedir. Hatta bu gibi yapılarla mücadele etmek için karşı-misyoner kuruluşlar oluşturulmuştur. ${ }^{58}$ Mesihi Yahudiler ise kendilerine karşı yapılan bu saldırıları, Pavlus'un "1şığ1 görmesi" 59 öncesinde yaptığı saldırılara benzetmekte ve Yahudi mirasının ve kimliğinin terk edilerek asimile etme anlamında misyonun bir parçası olmadıklarını iddia etmektedirler. Onlara göre Mesihi Yahudiler tıpkı Pavlus'un

53 Cohn-Sherbok, "Modern Hebrew Christianity and Messianic Judaism”, 291.

54 Power, "Blurring the Boundaries: American Messianic Jews and Gentiles", 79.

55 Cohn-Sherbok, "Modern Hebrew Christianity and Messianic Judaism", 291.

56 Rudolph, "Messianic Judaism in Antiquity and in the Modern Era", 31.

57 Ariel, “Judaism and Christianity Unite!”, 199-200.

58 İngiltere'de “Operation Judaism” ile İsrail'de "Yad L'Achim” bu gruplardan bazılarıdır. Şenay, “19. Ve 20. Y.Y.'da Mûsevî- Hıristiyanlar”, 64.; Ariel, “A Different Kind of Dialogue?”, 321.

59 Mesihi Yahudiler İsa’yı “dünyanın ışı̆̆ı” olarak nitelemektedir. Pavlus'un “1şı̆̆ı görme” metaforu, onun Şam vizyonuna gönderme yapmakta ve İsa’yı kabulünü ifade etmektedir. 
"1şı̆̆ı görmesiyle" gerçekleri görmesi gibi kendilerinin de yalnızca Mesih'in tanıklığ için "şamdan tuttuklarını" ifade etmektedirler. ${ }^{60}$ Mesihi Yahudiler her ne kadar etnik olarak Yahudi oldukları için Yahudi milletinden sayılmaları gerektiğini iddia etseler de Yahudilerin çoğunluğunun görüşüne göre onlar başka bir dini kabul etmekle diğer Yahudilerle olan ulusal bağdan feragat etmiş olmaktadırlar. ${ }^{61}$

\section{Mesihi Yahudiliğin İnanç Esasları}

Mesihi Yahudi cemaatler inanç sahasında birbirlerinden oldukça farklı görüşler ortaya koymakla beraber, çoğunluğu İsa'nın tanrısallığı, teslis, Kutsal Kitap'ın otoritesi gibi konularda geleneksel Hıristiyanlığın görüşlerini benimser. ${ }^{62}$

Mesihi Yahudiler Hıristiyanlığın temel dogması olan teslis (trinity) inancını, tanrının üçlü doğası (triune) şeklinde ifade etmektedirler. Böylece Mesihi Yahudiler tanrının tekliğine vurgu yaparak Yahudilerce en çok eleştirilen üçlü bir tanrı inanışında olmadıkları izlenimini vermeye çalışırlar. ${ }^{63}$ Dahası kendi inançlarını desteklemek için Torah'dan çeşitli pasajları örnek olarak kullanmaktadırlar. Söz gelimi Tanrı'nın tek olmasının yanı sıra bileşik bir birlik olduğunun ifadesinin Yaratılış 1:1'de Tanrı'nın çoğul bir isimle (Elohim) kendisini tanıtmasında görülebileceğini savunmaktadırlar. ${ }^{64}$ Dolayısıyla Tanrı'yı çoklu bir birlik biçiminde düşünmenin Yahudi teolojisiyle de uyumlu olduğunu kanıtlamaya çalışmaktadırlar. Aynı zamanda Tanrı'nın Baba, Oğul ve Kutsal Ruh olarak tecelli eden tek bir Tanrı olduğu, dünyadaki her ilahi eylemin Oğul aracılığıyla Ruh'un kudreti içinde icraatta bulunan Baba tarafindan gerçekleştirildiği ifade edilmektedir. ${ }^{65}$

Mesihi Yahudilere göre İsa, Hıristiyanların inandığı gibi hem tam bir Tanrı hem de tam bir insandır. İsa'nın ismi Mesihi Yahudilerce İbranice karş1lığı olan Yeşua şeklinde kullanılır. O, Yahudilerin uzun zamandır bekledikleri Mesih’tir. Mesihi Yahudilikte, Evanjelik Hıristiyanlarda olduğu gibi Mesih'in ikinci gelişine büyük önem atfedilmiştir. Mesihi Yahudiler İsa'yı kabul etmekle Yahudiliği kemale erdirdiklerini iddia etmektedir. ${ }^{66}$ Mesihi Yahudilerin İsa ile ilgili inançları UMJC'nin resmi bildirisinde şöyle ifade edilmektedir:

60 Gershon Nerel, "Primitive Jewish Christians in the Modern Thought of Messianic Jews", 421.

61 Cohn-Sherbok, Messianic Judaism, 203.

62 Richard Harvey, "In Search of Messianic Jewish Theology”, Mishkan 57 (2008), 7-10.

63 Juster and Hocken, The Messianic Jewish Movement, 35.

$64 \mathrm{https} / / /$ iamcs.org/about-us/belief, 10.29.2020.

65 https://www.umjc.org/statement-of-faith, 29.10.2020.

66 Gershon Nerel, "Primitive Jewish Christians in the Modern Thought of Messianic Jews", Le judéo-christianisme dans tous ses états, ed. Simon Mimouni, F. Stanley Jones, (Paris: Cerf, 2001), 402. 
Zaman gelince İlahi Oğul, Yahudi bir bakireden doğan, gerçek ve mükemmel bir İsrailli, tüm ulusun tek başına tecessümü ve uygun bir temsilcisi olan bir insan- Mesih Yeşua haline dönüştü. $\mathrm{O}$, Torah'taki mitzvotları (emir ve yasakları) kusursuz yerine getiren kutsal bir tzaddik (dindar Yahudi) olarak yaşadı.

Yeşua, İsrail ve tüm dünyanın günahları için bir kefaret olarak öldü. Yüceltilmesi için İsrail'e vaat edilen yeniden dirilişin ilk nüvesi olarak ölümden bedensel biçimde dirildi. O, semaya yükseldi ve İsrail'in Mesihi olarak yaratılışın sonuna kadar sürecek bir yetkiyle Tanrı'nın sağındaki tahta oturdu. Tanrı, Bedensel olarak Mesih'e katılıp İsrail'e vaat edilen Yeni Ahit olgunluğunun ilk temsilcileri olsunlar diye Kutsal Ruh'u Yeşua takipçileri topluluğunun üzerine yağdırdı. Bu ilk dönem Yahudi topluluğuna Tanrı, uluslar arasından ortaklar ilave etti.

Mesih'in topluluğu, Yahudi topluluğu ve uluslar içerisinde çeşitli biçimlerde ifadesini bulan tek bir topluluktur.

Bütün topluluk içerisindeki birlik ve sevgi, Baba tarafından gönderilen Tek olarak Yeşua'nın rolünü ve Tanrının İsrail ve uluslar için Mesih'teki gayesini onaylamaktadır. ${ }^{67}$

Mesihi Yahudiler Kutsal Kitap ile ilgili olarak Hıristiyanlar gibi hem Eski Ahit'in hem de Yeni Ahit'in tanrısal vahiy olduğunu kabul etmektedirler. Ancak hareket mensupları, İsa'nın gelişi ile birlikte Yahudi kutsal metninin hükmünün kalmadığını iddia eden Hıristiyan anlayışın aksine Tanah ve Yeni Ahit metinlerinin birbirini tamamladığını savunmaktadırlar. Bunun yanı sıra Tanah'ın ilk beş kitabı olan Torah'a ayrı bir önem atfetmektedirler. Torah'ın Yahudilere tanrısal bir hediye olduğunu, onun her nesilde uygulanması gereken evrensel davranış normları sunan bir kitap olduğunu kabul ederler. ${ }^{68}$ Tanah ve Yeni Ahit'i inanç konusunda en yüksek ve nihai otorite olarak kabul ederken, Tanah metinlerinin yalnızca Yeni Ahit vasıtasıyla açıklanabileceğini savunmaktadırlar. ${ }^{69}$

\section{Mesihi Yahudilikte İbadet ve Bayramlar}

Mesihi Yahudiler ibadetlerini kilisede değil sinagogda yerine getirmektedir. Mesihi Yahudi sinagoglar mimari olarak Yahudi sinagoglardan farklı olsa da içindeki yerleşim düzeni ve objeler aynıdır. Sinagogda Mesihi Yahudi ayinini Mesihi rabbi dedikleri dini lider yönetir ancak bu rabbiler geleneksel Yahudilikte kabul edildiği gibi Yeşivalarda yetişmemiştir. ${ }^{70}$ Mesihi Yahudi ibadetinin en dikkat

67 Adıbelli, “İsa'nın 'Meşiah’a Dönüşümü”, 259. https://www.umjc.org/statement-of-faith, 29.10.2020.

68 https://www.umjc.org/statement-of-faith, 29.10.2020.

69 Cohn-Sherbok, Messianic Judaism, 175.

70 Şenay, “19. ve 20. Y.Y.'da Mûsevî-Hıristiyanlar”, 66. Mesihi Yahudi rabbiler Messianic Jewish Theological Institute ve Netzer David International Yeshiva'da gerekli temel eğitimleri aldıktan sonra UMJC ve IAMCS aracıllğıyla görevlendirilir. David Rudolph and Elliot Klayman, "Messianic Jewish Synagogues", ". Introduction to Messianic Judaism: Its Ecclesial Context and Biblical Foundations, ed. David Rudolph \& Joel Willits, (Grand Rapids: Zondervan, 2013), 44. 
çekici yönü genellikle müzik ve dans eşliğinde dua edilmesidir. Mesihi Yahudilere göre duanın özü İsa ile birleşmek ve onun içinde, onun aracıllğıyla dua etmektir. ${ }^{71}$ Dua esnasında Yahudilere özgü ibadet objeleri de kullanılmaktadır.

Mesihi Yahudilerin büyük bir çoğunluğu geleneksel Yahudilikte kutsal kabul edilen günleri kutlamaktadır. Ancak Yahudilikteki bu kutsal günlerin anlamı Mesihi Yahudiler tarafından Hıristiyan geleneğin inançlarıyla bağlantılı hale getirilerek yorumlanmış ve kutsal günlerde icra edilen ayinlere özellikle İsa ile ilgili dua ve ilahiler eklenmiştir. Böylece her kutsal günün merkezine İsa yerleştirilmiş olur. Mesihi Yahudilikte bayramlar Kutsal Kitap'a göre belirlendiğinden hem Hiristiyan kiliselerinin takviminden hem de bazen rabbinik takvimden farkl1lık gösterebilir. ${ }^{72}$

Yahudiliğe göre haftanın en kutsal günü kabul edilen Şabat, Mesihi Yahudilerce de kutsal kabul edilmektedir. Davut'un Mezmurları'nda anlatılan ibadete göre modellenen Mesihi Yahudi Şabat ayini, geleneksel Yahudi ayinin yanı sıra genellikle şark1, dans ve müzik içerir. Bu yönüyle Mesihi Şabat ayini, geleneksel sinagog ayininden daha eğlencelidir. Ortalama Mesihi sinagog ayininde coşkulu şarkı ve dans olmasına rağmen, bazı Mesih cemaatleri siddur ${ }^{73}$ temelli daha klasik bir sinagog ayini düzenler. ${ }^{74}$ Şabat'ta Amida ${ }^{75}$ duasını okumak da Mesihi Yahudiler arasında yaygındır. Rabbinik kökenli olan Şabat mumlarının yakılması Yeni Ahit'te yasaklanmadığı için Mesihi Yahudiler bu uygulamayı sürdürmektedir. Mesihi Yahudilere göre bu uygulama İsa'nın "dünyanın ışı̆̆ı" olmasını sembolize eder. ${ }^{76}$

Geleneksel Yahudilikte İsrailoğullarının Mısır'dan çıkışı anısına kutlanan Fısıh, Mesihi Yahudilerce geleneksel anlamını korumakla birlikte İsa Mesih'in aracılığıyla insanlığın günahtan çıkışını da ifade eder. Mesihi Hagada ${ }^{77}$, Fısıh kuzusunun

71 Mark Kinzer, "Pots, Pans \& Seraphim: Messianic Jewish Prayer in its Heavenly Context", Hashivenu Forum 2017, 4.

72 Juster and Hocken, The Messianic Jewish Movement, 40.

73 Siddur, günlük ve Şabat'ta okunacak duaları ve buna ilaveten genellikle Roş ha-Şana ve Yom Kipur gibi önemli bayram dualarını da içeren Yahudi dua kitabıdır. Gürkan, Yahudilik, 249.

74 Rudolph, "Contemporary Judeo-Christian Communities in the Jewish Diaspora", 146.

75 Amida, Yahudi ibadetinin cemaat halinde ve ayakta okunan ana duasıdır. Orijinal biçimiyle on sekiz duadan oluştuğu için Şemone Esre veya ana dua olması sebebiyle Tefila olarak da isimlendirilir. Gürkan, Yahudilik, 241

76 Cohn-Sherbok, Messianic Judaism, 90.

77 Hagada, Fısıh bayramının ilk akşam yemeğinde okunan ve Mısır'dan çıkış hikayesi ile çeşitli kutsama, dua, Midraş ve Mezmur pasajlarından oluşan dua kitabıdır. Salime Leyla Gürkan, Yahudilik, (İstanbul: İSAM Yayınları, 2010),244. Mesihi Hagada, geleneksel Yahudiliğin Hagada'sından farklıdır. Mesihi Hagada' da bulunan dualar İsa'nı Mesihliğine ve tanrısallığına vurgu yapmaktadır. Bkz. Cohn-Sherbok, Messianic Judaism, 102-103. 
kutsal rolünü Mesih'in kutsal rolü ile karşılaştırır ve Yeni Ahit'te İsa'nın Fısıh kutlamalarına yapılan atıflar vurgulanır. ${ }^{78}$

Batı dillerinde Pentakost olarak ifade edilen Şavuot Mesihi Yahudi kutlamalarında hem Hıristiyan hem de Yahudi geleneğinin izlerini taşır. Bir yandan geleneksel Yahudilerin Şavuot kutlaması gibi evler ve sinagog çiçeklerle süslenirken diğer yandan okunan dua ve ilahiler İsa ve Kutsal Ruh üzerinedir. ${ }^{79}$

Tevrat’ta üç büyük hac bayramından biri olarak zikredilen Sukot bayramı, Yahudi dini içerisinde Mısır'dan çıkış sürecinde çölde geçirilen günlerle ilişkilendirilmiştir. ${ }^{80}$ Mesihi Yahudiler ise bu günü geleneksel anlamın yanı sıra İsa'nın doğum günü olarak da kutlamaktadır. ${ }^{81}$ Mesihi Yahudilere göre Tanrı bu günde bir Yahudi olarak insan formu almış ve yarattıklarıyla birlikte yaşamıştır. ${ }^{82}$ Sukot ayininde geleneksel Yahudilikte olduğu gibi bu güne özel Tevrat bölümleri ile Yeni Ahit’ten İsa'nın Sukot kutlamasına katıldığıyla ilgili pasajlar (Yuhanna 7:1-52) okunur. Bu günde geleneksel Yahudilikte olduğu gibi çadırlar kurulur. Bu atmosferin İsa'nın doğumunu canlandırdığı düşünülür. ${ }^{83}$

Yahudilerin yeni yılı olan Roş ha-Şana Mesihi Yahudilere göre İsa Mesihe inananların gelecekte bir araya gelmesini ifade eder. ${ }^{84}$ Aynı zamanda Mesihi Yahudiler, Yeni Ahit'te "Rabbin kendisi, bir emir çağrısıyla, başmeleğin seslenmesiyle, Tanrı'nın borazanıyla gökten inecek. Önce Mesih'e ait ölüler dirilecek. Sonra biz yaşamakta olanlar, hayatta olanlar, onlarla birlikte Rab'bi havada karşılamak üzere bulutlar içinde alınıp götürüleceğiz. Böylece sonsuza dek Rab'le birlikte olacağız." 85 pasajındaki “Tanrı'nın borazanı"nı Roş ha-Şana'da çalınan şofar ile bağlantılı görmektedir. Bu nedenle şofar Mesihi Yahudiler için İsa'nın yeniden geleceği günün müjdecisidir. ${ }^{86}$

78 David, J. Rudolph, "Contemporary Judeo-Christian Communities in the Jewish Diaspora", Encyclopaedia of the Jewish Diaspora, ed. M. Avrum Ehrlich, I, Chicago: ABC-Clio-LLC, 2008, 147.

79 Bu günde Messihi Yahudilerin okuduğu dua ve ilahiler için bkz. Cohn-Sherbok, Messianic Judaism, 107-108.

80 Gürkan, Yahudilik, 165.

81 Mesihi sinagoglarda genellikle Noel kutlanmamaktadır. Noel, cemaatin birlikte kutladığı bir bayram değildir; bazen bireysel olarak kutlanır. Rudolph, "Contemporary Judeo-Christian Communities in the Jewish Diaspora”, 147.

82 Rudolph, "Contemporary Judeo-Christian Communities in the Jewish Diaspora”, 146.

83 Cohn-Sherbok, Messianic Judaism, 110.

84 Cohn-Sherbok, Messianic Judaism, 113.

85 1. Selanikliler 4:16-17.

86 Juster and Hocken, The Messianic Jewish Movement, 41. 
Yahudi takvimindeki en kutsal gün olan ve günahların af olunacağı bir kefaret günü olduğuna inanılan Yom Kipur, Mesihi Yahudiler için de kutsal bir gündür. Ancak onlara göre bugün bir kefaret gününden ziyade bir şükran günüdür. Tanrıya İsa Mesihi gönderdiği için şükredilir. ${ }^{87}$ Zira Mesihi Yahudiler, tıpkı Hıristiyan teolojisinde olduğu gibi İsa'nın ölümü vasıtasıyla günahlardan arındıklarına inandıklarından bu günü Tanrı'ya şükran günü olarak kutlamaktadırlar. ${ }^{88}$ Bazıları bu günler için geleneksel duaların çoğunu kullanırken, daha az litürjik yönelimli olanlar yalnızca İncil içeriğini vurgular ve en uygun Mesih Yahudi övgü ve ibadet müziğini kullanır. ${ }^{89}$

Bunlardan başka Yahudilerin Tevrat sonrası döneme dayandıkları için küçük bayram olarak nitelendirdikleri Hanuka ve Purim, Mesihi Yahudilerin kutladığı diğer bayramlardır. Ancak bu bayramlar da tıpkı diğer bayramlarda olduğu gibi Mesihi Yahudiler için farklı anlamlar barındırır. Mesihi Yahudilere göre Hanuka, "dünyanın ışığı olan” İsa'ya inananların Tanrı'nın mabedinde sonsuza dek yaşayacaklarını sembolize eder..$^{90}$ Purim Yeni Ahit’te geçmese de Mesihi Yahudilerin çoğunluğu tarafından kutlanan bir bayramdır. Bu bayram çocukları eğitmeye ağırlık verilen bir zamandır. Esther'in hikayesini anlatan mizahi oyunlar oynanır ve eğlenceli toplant1lar yap1lır. ${ }^{91}$

Mesihi teolog Arnold G. Fruchtenbaum ${ }^{92}$ bayramların bir kısmını ya da tamamını kutlamanın belirli faydaları olduğunu ifade ederek bunları şöyle sıralar:

......Birincisi, inanmayan Yahudi halkıyla bayramın Yeşua (İsa)'nın Mesihliğini nasıl işaret ettiğini gösteren inancı paylaşmak için iyi fırsatlardır.

İkincisi, kendimizi Yahudi halkıyla bir tutmanın iyi bir yolunu sunuyorlar. Bu tanımlama meselesi, inancımızın Yahudiliğine bir tanıklık olarak çok önemlidir.

87 Rudolph, "Contemporary Judeo-Christian Communities in the Jewish Diaspora”, 146.

88 Arnold G. Fruchtenbaum, The Remnant of Israel: The History, Theology, and Philosophy of the Messianic Jewish Community, (United States of America: Ariel Ministries, 2011), 139.

89 Juster and Hocken, The Messianic Jewish Movement, 41.

90 Cohn-Sherbok, Messianic Judaism, 128-129.

91 Juster and Hocken, The Messianic Jewish Movement, 42.

92 Arnold G. Fruchtenbaum tanınmış bir Mesihi Yahudi teologtur. 1970'lerde kaleme aldığı Hebrew Christianity: Its Theology, History, and Philosophy adl eserinde kendisini bir İbrani Hıristiyan olarak tanımlamış ve Mesihi Yahudilik ile ilgili şüphelerini dile getirmiştir. İbrani Hıristiyanları kilisenin ayrılmaz bir parçası olarak gören Fruchtenbaum, din değiştiren Yahudilerin yerel kiliselerin bir üyesi olması gerektiğini savunur. Ancak bundan birkaç yıl sonra Fruchtenbaum görüşlerini değiştirmiş ve Mesihi Yahudi cemaatlerin kurulmasında etkili olmuştur. İsa'ya inanan Yahudilerin bağımsız cemaat kurma ve diledikleri takdirde Yahudi ayinlerini yerine getirme hakkını savunmuştur. Ariel, “Judaism and Christianity Unite!”, 213. 
Üçüncüsü, Yahudi kültürü ve tarihini öğretmek için bir temel sağlarlar. Bu, özellikle Yahudi inananların (Mesihi Yahudilerin) çocuklarına Yahudiliği aşılamak için önemlidir.

Dördüncüsü, Tanrı'ya ibadet etmek ve Yahudi tarihi boyunca yaptıklarından dolayı ve Mesih'in Yahudi Kutsal Günlerini gerçekleştirirken bizim için yaptıklarından dolayı O'na teşekkür etmek için bir firsat olarak hizmet ediyorlar

Öyleyse önümüzdeki görev, İsa Mesih'e olan inancımızla ilgili Yeni Ahit’in öğretisine uygun hale getirmek için bu ayinlerin çoğunu veya tamamını yeniden çalışmaktır...... ${ }^{93}$

Her ne kadar Mesihi Yahudi cemaatler ilk kuruldukları zamandan itibaren Yahudi dini geleneğinin uygulanması gerektiği konusunda açık görüş belirtse de yapılan alan çalışmalarında cemaat üyelerinin dini geleneği sürdürme ve sürdürülmesinin gerekliliği konusunda zayıf oldukları görülmektedir. ${ }^{94}$ Bunun yanı sıra bu eylemlerin yerine getirilmesinin temelde kurtuluşu sağlamayacağı inancındadırlar. Nitekim Hıristiyanlıkta olduğu gibi Mesihi Yahudilikte de kurtuluş ancak Mesihin inayeti ile mümkündür.

\section{SONUÇ}

Huristiyan coğrafyada önce Puritanizmin etkisi, sonra reformasyon ve nihayetinde modern çağın sonlarında evanjelizmin yükselişiyle birlikte Yahudiler tarihte misyonu olan çok özel bir halk olarak görülmeye başlanmıştır. Yahudilere yönelik bu ilgiye ek olarak İsrail Devleti'nin kurulması ve Altı Gün Savaşı gibi eskatolojik açıdan Mesih'in ikinci gelişi ile ilişkilendirilen olaylar kimliklerine sahip çıkma konusunda Mesihi Yahudileri cesaretlendirmiştir. Tüm bu şartlar senkretik bir dini hareket olarak Mesihi Yahudiliğin doğuşuna zemin hazırlamıştır.

Yahudi milli bilincindeki bu uyanış bazı diğer Yahudi Hıristiyan grupların ortaya çıkmasını da sağlamıştır. Mesihi Yahudileri diğer Yahudi Hıristiyan gruplardan ayıran en önemli özellik kendilerinin Yahudi halkı Hıristiyanlaştırma niyetinde olmadıkları aksine onların gerçek Yahudi olmalarını sağlamaya çalıştıkları iddiasını dillendirmeleridir.

Mesihi cemaatler kendilerinin hem tam bir Huristiyan hem de tam bir Yahudi olduklarını savunmaktadırlar. Aynı zamanda Mesihi Yahudiler, hem Yahudilerin hem de Hıristiyanların dinsel anlamda kendilerini yanlış konumlandırdığını ima etmektedirler. Buna göre, Tanrı'nın Tanah'ta vaad ettiği Mesih nihayet geldiğinde Yahudiler onu kabul etmekten kaçındıkları için; Hıristiyanlar ise Mesih'i kabul etseler de kiliseyi Tanrı'nın seçilmiş halkına yabancılaştırdığı için hata yapmıştır. Bu

93 Arnold G. Fruchtenbaum, The Remnant of Israel, 137-138.

94 Bkz. Senay, "The Making of a Tradition: Jewish Christianity", 33. 
noktada Mesihi Yahudilere göre kendileri tam da olması gereken yerde durmaktadır: Bir yandan Yahudi milleti olarak Tanrı'nın onlara lütfettiği ayrıcalıklı konumu terk etmeden yaşamaktadırlar; öte yandan Mesih İsa'yı kabul ederek tanrısal krallıkta yer almayı hak etmektedirler. Böylece yeni bir dini hareket olma iddiasında değil, aksine otantik bir dini gelenek olarak Tanrı'nın gerçek dinini temsil ettikleri izlenimi vermektedirler.

\footnotetext{
Hakem Değerlendirmesi: Dış bağımsız.

Çıkar Çatışması: Yazar çıkar çatışması bildirmemiştir.

Finansal Destek: Yazar bu çalışma için finansal destek almadığını beyan etmiştir.
}

Peer-review: Externally peer-reviewed.

Conflict of Interest: The author has no conflict of interest to declare.

Grant Support: The author declared that this study has received no financial support.

\section{Kaynakça/References}

Adıbelli, Ramazan. “İsa’nın ‘Meşiah’a Dönüşümü: Mesihi Yahudilikte Mesihlik Fenomeni”. İnsan ve Toplum Bilimleri Araştırmaları Dergisi, 5/2 (2016), 242-270.

Ariel, Yaakov. An Unusual Relationship: Evangelical Christians and Jews. New York and London: New York University Press, 2013. Ariel, Yaakov. "A Different Kind of Dialogue? Messianic Judaism and Jewish Christian Relations". CrossCurrents 62/3 (2012), 318-327.

Ariel, Yaakov. "Messianic Judaism", The Jewish Annotated New Testament, Ed. Amy-Jill Levine and Marc Zvi Brettler, 756-759, New York: Oxford University Press, 2011.

Ariel, Yaakov. "Judaism and Christianity Unite! The Unique Culture of Messianic Judaism". Introduction to New and Alternative Religions in America, ed. Eugene V. Gallagher, W. Michael Ashcraft, 2/191-221. London: Greenwood Press, 2006.

Ariel, Yaakov. Evangelizing the Chosen People. USA: The University of North Carolina Press, 2000.

Batuk, Cengiz. Tarihin Sonunu Beklemek: Ortadoğu Dinlerinde Eskatoloji Mitosları. İstanbul: İz Yayıncilık, 2003.

Cohn-Sherbok, Dan. "Modern Hebrew Christianity and Messianic Judaism". The Image of the Judaeo-Christians in Ancient Jewish and Christian Literature. ed. Peter J. Tomson \& Doris Lambers-Petry, 287-298. Tübingen: Mohr Siebeck, 2003, 287-298.

Cohn-Sherbok, Dan. Messianic Judaism, London and New York: Continuum, 2000.

Curtis, Rodney. "Evangelical Anglican missionaries and the London Jews Society: Palestine Place at Bethnal Green and related developments, 1813-1895”. Jewish Historical Studies 50/1 (2018), 69-100.

Friedman, Jerome. "The Myth of Jewish Antiquity: New Christians and Christian-Hebraica in Early Modern Europe", Jewish Christians and Christian Jews From the Renaissance to the Enlightment, ed. Richard H. Popkin and Gordon M. Weiner, (Kluwer Academic Publishers, 1994), 35-55.

Fruchtenbaum, Arnold G. Hebrew Christianity: Its Theology, History and Philosophy. Michigan: Baker Book Hause, 1974. Fruchtenbaum, Arnold G. The Remnant of Israel: The History, Theology, and Philosophy of the Messianic Jewish Community, United States of America: Ariel Ministries, 2011. 
Gidney, W. T. The History of the London Society for Promoting Christianity Amongst the Jews from 1809 to 1908. London: London Society for Promoting Christianity Amongst the Jews, 1908.

Gidney, W.T. Missions to Jews. 10. Bask1, London: London Society for Promoting Christianity amongst the Jews, 1912.

Greisiger, Lutz. "Israel in the Church and the Church in Israel: The Formation of Jewish Christian Communities as a Proselytising Strategy Within and Outside The German Pietist Mission to the Jews of the Eighteenth Century". Pietism and Community in Europe and North America, 16501850. ed. Jonathan Strom. 129-153. Leiden, Boston: Brill, 2010.

Gündüz, Şinasi. Hıristiyanlık. İstanbul: İsam Yayınları, 2020.

Güngör, Ali İsra. Evanjelikler. İstanbul: İlgi Kültür Sanat Yayıncılık, 2016. Gürkan, Salime Leyla. Yahudilik. İstanbul: İSAM Yayınları, 2010.

Harman, Ömer Faruk. "Yahudi Hiristiyanlığı”. TDV İslam Ansiklopedisi, 43, 184-187. Harvey, Harvey. "In Search of Messianic Jewish Theology". Mishkan 57 (2008), 7-

Kinzer, Mark S.“Twenty-First Century Messianic Judaism: Evangelical and Post EvangelicalTrajectories”. Hebrew Studies 57, 2016, 359-366.

Kinzer, Mark. "Pots, Pans \& Seraphim: Messianic Jewish Prayer in its Heavenly Context”, Hashivenu Forum 2017, 1-7. http://hashivenu.org/forum-papers/ 05.12.2020.

Kohn, Rachael L.E ."Ethnic Judaism and the Messianic Movement”. The Jewish Journal of Sociology, 29/2 (1987), 85-96.

Költsch, Anke. "Foundations, İnstitutes, Charities, and Proselytes in the Early Modern Holy Roman Empire". Jewish History, 24 (2010), 87-104.

Kutsal Kitap, İstanbul: Kitabı Mukaddes Şirketi, 2001.

Nerel, Gershon. “ 'Messianic Jews' in Eretz-Israel (1917-1967) Trends and Changes in Shaping Self Identity". Mishkan 27 (1997), 11- 25.

Nerel, Gershon. “Attempts to Establish a 'Messianic Jewish Church' in Eretz-Israel”. Mishkan 28 (1998), 28-35.

Nerel, Gershon. "Primitive Jewish Christians in the Modern Thought of Messianic Jews". Le judéochristianisme dans tous ses états, ed. Simon Mimouni, F. Stanley Jones, (Paris: Cerf, 2001).399-425.

Power, Patricia A. "Blurring the Boundaries: American Messianic Jews and Gentiles". Nova Religio, 15/1 (August 2011), 69-91

Popkin, Richard H. "Christian Jews and Jewish Christians in the 17th Century", Jewish Christians and Christian Jews From the Renaissance to the Enlightment, ed. Richard H. Popkin and Gordon M. Weiner, (Kluwer Academic Publishers, 1994), 57-72.

Olgun, Hakan. Sekülerliğin Teolojik Kurgusu: Protestanlık. İstanbul: İz Yayıncılık, 2006.

Rudolph, David. "Messianic Judaism in Antiquity and in the Modern Era". Introduction to Messianic Judaism: Its Ecclesial Context and Biblical Foundations, ed. David Rudolph \& Joel Willits, 2136, Grand Rapids: Zondervan, 2013.

Rudolph, David. "Contemporary Judeo-Christian Communities in the Jewish Diaspora". Encyclopaedia of the Jewish Diaspora, ed. M. Avrum Ehrlich, I, Chicago: ABC-Clio-LLC, 2008, 146-150.

Rudolph David and Klayman, Elliot. "Messianic Jewish Synagogues". Introduction to Messianic Judaism: Its Ecclesial Context and Biblical Foundations, ed. David Rudolph \& Joel Willits, 3750, Grand Rapids: Zondervan, 2013. 
Sağ, Mustafa Kaan. "Londra Yahudiler Cemiyeti İstanbul Misyonu ve Hasköy İngiliz Okulu". Belleten 79/285, (2015), 627-657.

Salihoğlu, Mahmut. "Marranolar ve Dini İnançları”. Ekev Akademi Dergisi 15/49, (Güz 2011), 105-115.

Sobel, B. Zvi. "Jews and Christian Evangelization: The Anglo-American Approach", American Jewish Historical Quarterly, 58/2 (December, 1968), 241-259.

Senay, Bülend. “The Making of Tradition”. Mishkan 27 (1997), 31-34.

Şenay, Bülent. “19. Ve 20. Y.Y.’da Mûsevî-Hıristiyanlar-Hibridite, Dînî Kimlik ve Gelenek-”. 2000. Yılında Hıristiyanlık (Dünü, Bugünü ve Geleceği), Dinler Tarihi Araştırmaları-III (Sempozyum, 09-10 Haziran 2001, Ankara), (Ankara: Dinler Tarihi Derneği Yayınları/3, 2002), 55-69.

UMJC, Statement of Faith, Erişim Tarihi:29.10.2020. https://www.umjc.org/statement-of-faith IAMCS, About Us, Erişim tarihi: 29.10.2020. https://iamcs.org/about-us/belief, 